\title{
Training helps reduce pesticide risks
}

$\mathrm{C}$ ommunicating pesticide safety information to California's 800,000 agricultural workers is a daunting task. California production agriculture applies about 202 million pounds of pesticide active ingredients each year, over a vast geographic area and on hundreds of different crops, livestock and nursery products.

"We use a greater variety of pesticides in California, and a greater array of application methods and timing, than regions such as the Midwest, where growers produce a few major crops within well-defined seasons," says Patrick O'Connor-Marer, pesticide training coordinator for the UC Statewide IPM Project.

Furthermore, the state's agricultural workers are drawn from a large and constantly changing pool, primarily of migrant and seasonal workers from Mexico, as well as Southeast Asian and Punjabi immigrants and other non-Englishspeaking persons.

Since 1988, the UC IPM Project has been responsible for mandated training of California's pesticide applicators. With a staff of just three educators, a half-time writer, and one and onehalf support positions, its Pesticide Education Program (PEP) has devised innovative methods for managing a Herculean task.

Hands-on workshops. The program's initial efforts involved conducting 8-hour seminars for as many as 400 participants. These large seminars were not particularly engaging for participants nor were they effective in influencing pesticidehandling behavior, $\mathrm{O}^{\prime}$ Connor-Marer says.

Learning from this experience, PEP developed hands-on workshops. Conducted outside in facilities such as fairgrounds or large parks, the workshops accommodate as many as 420 participants divided into small groups of 15 people or less. The groups rotate through seven stations, covering topics such as personal protective equipment, mixing and loading, application equipment, leaks and spills, environmental protection, first aid, and cleanup and disposal methods. Some sessions are conducted in Spanish, Punjabi or other languages.

"People feel more comfortable asking questions in small groups," says Rupali Das of the California Occupational Health Surveillance and Evaluation Program, who has participated in several UC workshops. "It's more of a discussion."

Lacking the resources to conduct these workshops themselves, PEP staff offered 175 train- the-trainer workshops between 1993 and 2000,

with 4,410 individuals receiving certification. In

turn, these individuals trained more than

810,000 pesticide han-

dlers and agricultural

fieldworkers. In addition, some PEP workshops have targeted the healthcare workers, to improve reporting of pesticide illnesses and injuries.

Pesticide label comprehension. In 2000, PEP conducted a feasibility study among Hispanic farmers in Monterey County and Hmong farmers in Fresno County to determine if non-Englishspeaking individuals could acquire sufficient English skills to understand pesticide labels. In consultation with ESL (English as a Second Language) experts, program staff developed a 60 -hour course. In a recent evaluation, individuals were asked 75 questions about a pesticide label before and after taking the course; afterward, the number of correct answers increased by an average of $81.7 \%$, O'Connor-Marer says.

Outreach success. PEP's train-thetrainer programs illustrate that it is possible to leverage the efforts of a few staff in order to reach large numbers of people. In 1999, 247 participants were surveyed to assess the effectiveness of the train-the-trainer workshops; on average, each instructor trained 219

fieldworkers $(S D=670)$ and 35 pesticide handlers $(\mathrm{SD}=8)$.

The state's Pesticide Illness Surveillance Program reports that pesticide handlers and agricultural fieldworkers may be changing their behaviors. From 1989 through 1998, the state program, which relies on health care worker reports, found that topical illnesses definitely or probably caused by pesticide exposure dropped by $61 \%$ in agricultural workers and $57 \%$ in nonagricultural workers.

For more information go to: http:// www.ipm.ucdavis.edu/PEP/pepmenu.html. - Janet Byron 